This article has been accepted for publication in Medical Law Review Volume 26, Issue 1, 1 February 2018, pages 117-124, published by Oxford University Press.

DOI: https://doi.org/10.1093/medlaw/fwx041

\title{
PSYCHIATRIC INJURY CLAIMS AND PREGNANCY: RE (A MINOR) AND OTHERS V \\ CALDERDALE \& HUDDERSFIELD NHS FOUNDATION TRUST [2017] EWHC 824
}

\section{INTRODUCTION}

This claim arose following the alleged negligent delivery of a baby, RE, by the Defendant, Calderdale and Huddersfield NHS Foundation Trust. RE's claim for physical injury will not be the focus of this commentary, which instead focuses on the claims for psychiatric injury by her mother, LE, and her grandmother, DE. Both adults experienced post traumatic stress disorder (PTSD) as a result of observing the labour, which lasted approximately 10 hours.

Liability for psychiatric injury is treated differently in law from physical injury. There are additional control mechanisms and liability depends on whether the claimant is classified as a primary or secondary victim. There were two main issues that arose in relation to LE and DE's claims: (i) whether LE (the mother) was a primary victim and (ii) whether the sight of the birth was sufficient to be classed as a sudden shocking event. ${ }^{1}$ This commentary explores the reasoning and implications for the judge's findings that (i) LE was a primary victim and (ii) that the birth was a sudden shocking event. Both of these findings meant that LE and DE's clinical negligence claims were successful. It will be argued that both findings are justifiable based on existing principles of tort law. In addition, the finding that LE was a primary victim affirms the important principle that a fetus inside a pregnant woman is, legally, to be treated as a part of the woman's body.

\footnotetext{
${ }^{1}$ The commentary refers to this requirement as a 'sudden shocking event' as others have also done in this context, see Burrows, AS and Burrows, JH (2016) 'A shocking requirement in the law on negligence liability for psychatric illness: Liverpool Women's Hopsital NHS Foundation Trust $v$ Ronayne [2015] EWCA Civ 588' 24 Medical Law Review 278.
} 
The principled implications of a different finding would have been concerning and potentially wide-ranging. However, beyond that, the implications of the judgment do raise some concerns. In particular, the fact that birth can constitute a shocking event arguably challenges the work done to normalise pregnancy and childbirth and relatedly to de-medicalise it. ${ }^{2}$ Secondly, the possibility of an expansion in claims resulting from any loosening of the Alcock criteria requires careful analysis. It will be considered that the court, in reaching this decision, failed to take into account the implications of widening recovery, particularly for healthcare professionals, and resource pressures on the NHS. These two challenges will be explored following a consideration of the facts of the case and the legal principles that applied to it.

\section{THE FACTS}

The case concerned a clinical negligence claim which arose out of an alleged negligent delivery at a midwifery led unit run by the Defendant Trust. The baby suffered an acute profound hypoxic ischaemic insult immediately prior to delivery, which was found to be the result of a negligent delay. The difficulties in the baby's birth partly arose as she was expected to be macrosomic (being over a birth weight of $4.5 \mathrm{~kg}$ ). It was found that she probably suffered from shoulder dystocia during the course of delivery. The Claimants alleged that the Trust failed to anticipate the risk of shoulder dystocia, given that the baby was known to be large, and when that risk materialised they fell below the expected standard of care in dealing with it. Mr Justice Goss held that, in summary, there were negligent failures to: recognise the possibility of shoulder dystocia, diagnose the potential shoulder dystocia and, at that point of potential diagnosis, summon help immediately. The failure by the midwife to summon assistance was found to be negligent, as was the fact that she prevented the obstetrician from entering the room for

${ }^{2}$ See for example the discussion in Ebtehaj, F, Herring, J, Johnson, MH and Richards, M (eds), Birth Rites and Rights (Hart 2011). 
one minute when he did arrive. It was held that, as a result of these actions, there was a negligent delay in delivery of 11 minutes, which, if avoided, would have ensured RE avoided all damage.

In relation to the claim for psychiatric injury resulting from the negligence outlined above, LE and DE described seeing a 'lifeless' body and that RE's head was 'purple and swollen'. ${ }^{3}$ LE thought her baby was dead and it was held by the judge that LE's PTSD was caused by 'the birth of a flat, apnoeic baby'.4 Similarly, DE's claim was successful on the basis that she had observed the events of the birth and they were 'sufficiently sudden, shocking and objectively horrifying'.

\section{PSYCHIATRIC INJURY CLAIMS IN THE CLINICAL NEGLIGENCE CONTEXT}

The law on recovery for psychiatric injury is different depending on whether a person is deemed to be a primary or a secondary victim. Both potential classes of claimant need to show that they have a recognised psychiatric illness, which in this case was satisfied as both claimants had PTSD. Primary victims need to prove that they were in the zone of physical danger. ${ }^{6}$ This means that they only need to show that physical injury was foreseeable, not psychiatric injury. Therefore LE, being an active participant in the labour, and suffering the psychiatric injury as a result of events that occurred when RE was still partially inside her, was deemed to be a primary victim.

Consistency with existing principles of law required that LE be found to be a primary victim. Legally, a fetus is not a recognised person until birth. ${ }^{7}$ This is the case for claims brought by a child injured in utero as their claim only crystallizes at the point

\footnotetext{
${ }^{3}$ RE (a minor) and others $v$ Calderdale \& Huddersfield NHS Foundation Trust [2017] EWHC 824 para. 42.

4 Ibid para. 46.

5 Ibid para. 48.

${ }^{6}$ Page v Smith [1996] 1 AC 155.

7 Paton v BPAS [1979] QB 276.
} 
of birth. ${ }^{8}$ Therefore it would be inconsistent not to recognise a mother's ability to claim for an experience that took place before birth. In fact, it would appear nonsensical to argue that because RE's head was partially outside of LE's body that somehow this changed the legal position. Furthermore, in a practical sense LE was in the zone of physical danger, which she could not leave. Whilst childbirth in the UK is generally safe, it remains a potentially dangerous experience depending on various risk factors. ${ }^{9}$ Despite concerns about the impact this could have on expanding liability, some of which are identified later, it would have been inconsistent to have found any other way on this issue. In the context of pregnancy, the law must hold a firm line in protecting a pregnant woman's bodily autonomy and confirming this in the clearest possible terms in this case was the right thing to do. ${ }^{10}$

In contrast, there are additional control mechanisms for secondary victims, as outlined in Alcock $v$ Chief Constable of South Yorkshire.11 That case arose out of the Hillsborough disaster and was brought by friends and relatives of those who were crushed in the stadium. In summary, their unsuccessful claim for psychiatric injury was based on viewing their loved ones being crushed at the stadium (or its aftermath) through various forms of media or in person from other areas of the stadium. Alcock established three additional proximity criteria that secondary victims would have to satisfy to be able to recover for psychiatric injury: proximity of relationship, proximity of time and space, proximity of perception. None of these three criteria were at issue in

\footnotetext{
${ }^{8}$ Burton v Islington Health Authority; De Martell v Merton and Sutton Health Authority [1993] QB 204.

${ }^{9}$ In the UK the maternal mortality rate is low at 9 deaths per 100,000 live births, see World Health Organization, 'Maternal mortality ratio (modeled estimate, per 100,000 live births)' $<$ http://data.worldbank.org/indicator/SH.STA.MMRT?locations=GB $>$ accessed 1 June 2017. However, there are other injuries associated with childbirth and specifically shoulder dystocia which occurred in this case, see Gurol-Urganci, I, Cromwell, DA, Edozien, LC, Mahmood, TA, Adams, EJ, Richmond, DH, Templeton, A and van der Meulen, JH (2013) 'Third- and fourth-degree perineal tears among primiparous women in England between 2000 and 2012: time trends and risk factors' 120 BJOG: An International Journal of Obstetrics \& Gynaecology 1516.

10 Notwithstanding that in many instances the law has not always fully protected a pregnant woman's autonomy in this way, particularly in relation to women who are found to lack the capacity to make decisions, for a further discussion see Halliday, S, Autonomy and Pregnancy: A Comparative Analysis of Compelled Obstetric Intervention (Routledge 2016).

11 [1992] 1 AC 310.
} 
the present case given that DE was in a close relationship with the victims (she was the mother and grandmother), she witnessed the scene of the event directly as it happened and she viewed it with her own senses. However, the difficulty for DE was in establishing the final criteria set down in Alcock - that the injury must be caused by a sudden, shocking event. Lord Ackner described this as 'the sudden appreciation by sight or sound of a horrifying event, which violently agitates the mind.'12 Therefore a shocking or horrifying event that is gradual in nature would not generally be sufficient to establish liability.

There is a line of clinical negligence cases where the shocking event requirement was in issue and which help to elucidate this area of law. It is clear from these cases that there are inconsistencies as to how the law is applied and to which scenarios, particularly in the clinical context. For example, in North Glamorgan NHS Trust $v$ Walters $^{13}$ a mother successfully claimed damages for psychiatric injury suffered as a result of events leading to the death of her baby son. The Defendant Trust had failed to diagnose her son's acute hepatitis as a result of which he suffered a seizure witnessed by the mother. The sudden shocking event culminated in the mother agreeing to terminate life support and her baby son died in her arms. In Walters this event occurred over a 36 hour period yet was still treated as a sudden shocking event. In contrast, in Liverpool Women's Hospital NHS Foundation Trust v Ronayne ${ }^{14}$ a 36 hour deterioration in the claimant's wife's condition following a hysterectomy was not treated as a sudden shocking event. Wider issues appeared to have been taken into account in Ronayne, for example it was said that the claimant should have known what to expect and that he knew his wife's life was in danger. ${ }^{15}$ To some extent this is understandable, as witnessing a loved one in hospital inevitably involves some degree of expectation of

\footnotetext{
12 Ibid 401.

13 [2002] EWCA Civ 1792.

14 [2015] EWCA Civ 588.

15 Ibid para. 37.
} 
stress. However, there appears from the case law to be little consistency as to how this requirement is applied, with time clearly not the determinative factor.

In the present case both LE and DE's claims were found to satisfy the sudden shocking event requirement. Despite finding that LE was a primary victim, Goss J also went on to consider whether she would satisfy the requirements for a claim as a secondary victim in the event that he was wrong in that conclusion. Focusing on the sudden shocking event requirement, he said in relation to LE that 'this was an outwardly shocking experience that was exceptional in nature and horrifying as judged by objective standards and by reference to persons of ordinary susceptibility'.16 DE's claim succeeded on the basis that 'her first-hand observation of the first 15 minutes of life' was the triggering event for the PTSD, ${ }^{17}$ thereby focusing on the post-birth period. In relation to DE's claim there was very little separate analysis of how the sudden shocking event requirement applied to the birth itself.

The decision on this point could be criticised on the basis that childbirth is not a sudden event but takes place over an extended period of time. Even if the finding in relation to DE related to the post-birth observations of RE rather than the birth itself, again this was arguably still not sufficiently sudden given that the events leading up to it (i.e. the birth) lasted around 10 hours. However, it is important in these cases to focus on the key period in which the negligence occurred, which in this case lasted around one hour. If the midwives had responded differently within that period of time, the outcome would have been very different. In fact, the negligent delay in delivery was only a matter of 11 minutes. Therefore the arguably shocking element of the birth was appropriately found to be sudden, albeit that the overall experience may have lasted much longer.

\section{BIRTH AS A SHOCKING EVENT?}

\footnotetext{
${ }^{16}$ Above, n 3 para. 47.

17 Ibid para. 48.
} 
One difficulty with this case arises in relation to the finding that the birth was a shocking event. Of course, childbirth is in many ways shocking: it often occurs over an extended period of time, sometimes a matter of days, it is usually extremely painful and it can involve the risk of death or serious bodily injury for both the woman and child. Childbirth is often presented through imagery of pain and distress, albeit accompanied by subsequent joy. Therefore it is perhaps unsurprising that childbirth was found to be a 'sufficiently sudden, shocking and objectively horrifying'18 event in this case.

However, despite the obvious dangers of childbirth, it is a still normal life experience, which the human species relies upon for its existence. Turning what is a normal and necessary life experience into a medically and legally recognised cause of psychiatric harm ${ }^{19}$ has potentially dangerous consequences in the way that we view childbirth, both from a legal and social perspective. Thus, as McGuinness states 'we must recognise how law's manipulation of women and their (potential) reproductive choices shapes social norms and expectations. ${ }^{20}$ Similarly, when law frames childbirth as a sudden, shocking and horrifying event such that it can create psychiatric injury in others, it characterises childbirth as dangerous and abnormal.

Furthermore, the key difference between LE and DE's position was that DE could choose to leave if she found it too horrifying, LE could not; she was actively involved in the event and had to see it through. DE, whilst understandably wanting to provide support, ultimately did not have to be there if she found the events too shocking. Moreover, even if the birth was found, as in this case, to be sufficiently shocking, it would be so irrespective of the (failure of) medical intervention. Had LE given birth at home without any medical assistance, it is likely that a similar course of events would have unfolded given the size of her baby. Yet in those circumstances there would have

\footnotetext{
18 Above, n 3 para. 48.

${ }^{19}$ For an interesting discussion of these issues see Ahuja, J (2015) 'Liability for psychological and psychiatric harm: the road to recovery' 23 Medical law review 27.

20 McGuinness, S, 'Legal commentary - giving birth, foetal subjectivity, and harm' in Smith, S and others (eds), Ethical Judgments: Re-Writing Medical Law (Hart 2016) 241.
} 
been no professionals on whom to impose a duty of care, meaning that LE and DE would not have been able to recover for their, probably identical, injury. Should the fact that this 'sudden shocking event' occurred within a healthcare setting be sufficient to impose liability and change what was undoubtedly an extremely distressing experience into a legally recoverable one? The failure to act did not cause the sudden shocking event; it failed to prevent it. Of course once a healthcare professional is involved and negligently fails to take steps to avoid the unwanted outcome the law should step in to provide redress and therefore the judgment is evidently legally justifiable. However, whilst recovery in the individual case may seem fair, there is a symbolic risk that the decision articulates something harmful about how reproduction is viewed by law and society. Characterisations that frame childbirth as shocking and horrifying could have a wider impact on how pregnant women are treated in law and undermine the struggle to ensure a pregnant woman's autonomy is respected.

\section{IMPLICATIONS OF EXPANDING RECOVERY FOR PSYCHIATRIC INJURY}

Whilst the decision may be justifiable on legal principles, the implications of extending the scope of recovery for secondary victims must also be considered. In particular, the potential cost to the NHS, and therefore the public, could continue to grow as secondary victim claims for psychiatric injury rise. Burrows and Burrows state that Ronayne was a 'very rare example of a case in which a medical negligence claim for psychiatric illness by a secondary victim succeeded'. ${ }^{21}$ However, particularly given the finding in this case, it must be remembered that the fact there are cases where claims for psychiatric injury have been successful will impact upon the out of court settlement of the many other cases that do not reach trial. ${ }^{22}$

\footnotetext{
${ }^{21}$ Above, $\mathrm{n} 1281$.

22 This is because so few clinical negligence cases (and civil law cases generally) reach trial, see A Ritchie QC, 'Summary of the Personal Injury and Clinical Negligence Claims Market in England
} 
Furthermore, clinical negligence litigation costs and settlement awards are growing as data from NHS Resolution confirms. Over $£ 1.1$ billion worth of clinical negligence payments were made in $2012 / 13$ followed by a slight drop for two years, rising to a peak of over $£ 1.3$ billion in the $2015 / 16$ financial year. ${ }^{23}$ Furthermore, as at 31 March 2016, an estimate of potential clinical negligence liabilities stood at $£ 56$ billion. ${ }^{24}$ As a society we have to consider how best to allocate scarce healthcare resources. That is not strictly a legal question and therefore the courts should not be criticised for decisions that expand liability. However, for those with a wider interest in the healthcare context of the UK, the political dimension of this decision should not be ignored. Following the Court of Appeal's rejection of the claimant's claim for psychiatric injury in Ronayne, the lawyer representing the Trust said:25

To have allowed recovery in this case, would be to allow recovery for almost any person who developed a psychiatric disorder after witnessing their loved ones in a hospital setting following treatment for clinical negligence. Such a wide ambit for recovery would significantly increase the NHS's liability for clinical negligence claims.

This case raises important questions that need to be asked in light of well-publicised financial constraints on the NHS. These difficult birth injury cases usually only turn on a matter of minutes where difficult judgements are made under high-pressure circumstances. Of course healthcare professionals should be and are trained to deal with

and Wales July 2015'

<http://www.9goughsquare.co.uk/uploadedFiles/CN\&PIMarketReview2015AR.pdf> accessed 5 June 2017. Also see NHS Litigation Authority, 'Annual report and accounts 2015/16'

<http://www.nhsla.com/AboutUs/Documents/NHS Litigation Authority Annual Report and Ac counts 2015-2016.pdf $>$ accessed 5 June 2017.

${ }^{23}$ The NHS Litigation Authority, 'Factsheet 2: financial information - 2015-16'

$<$ http://www.nhsla.com/currentactivity/Documents/NHS\%20LA\%20Factsheet\%202\%20\%20financial\%20information\%20-\%202015-16.pdf > accessed 1 June 2017.

24 Ibid.

25 Miller, J (2015) “"Michelin Man" case deflates' 165 New Law Journal 4. 
those situations. However, if costs do noticeably increase and litigation has a detrimental impact on those already under strain NHS employees, we could reach a situation where NHS hospitals feel they have no choice but to prevent friends and family from being present with a patient to avoid potential liability. This is clearly an extreme scenario which is not yet close to materialising, but the unintended consequences of any expansion of liability in this context need to be taken seriously.

\section{CONCLUSION}

This case has the potential to broaden the scope of recoverability for psychiatric injury for both primary and secondary victims. It has been argued that the claim by the former was justified but the latter raises some concerns, particularly in relation to the applicability of the sudden shocking event requirement to childbirth and floodgates arguments. It remains to be seen whether this case is an exception to the generally restrictive approach taken to secondary victim liability or whether it represents an emerging trend to expand liability in this area. However, the possibility of a loss of certainty and the implications of any expansion of liability in the NHS context are factors that should not be ignored. 